\title{
All hands on deck as cases of COVID-19 surge
}

\author{
Cite as: CMAJ 2020 April 14;192:E415-6. doi: 10.1503/cmaj.1095859
}

Posted on cmajnews.com on March 26, 2020

anada won't have enough health care workers to deal with the expected surge in cases of COVID-19 without major changes in the way care is managed, said Dr. Michael Warner, section chair for critical care with the Ontario Medical Association.

If $30 \%$ of Ontarians fall ill with COVID19 as projected by health officials, around $5 \%$ or 217500 patients will end up in an intensive care bed, Warner explains. "If we have 10000 critically ill patients all at once, which is theoretically possible, there's no system that can handle it," he told CMAJ.

Across the country, health systems and organizations are working on creative ways to make the most of existing health human resources as Canada's outbreak escalates. Yet ensuring that the right numbers of health professionals with the right mix of skills are working in the right places is already a challenge in Canada and will be much more difficult when many health workers may fall ill.

Medical regulators across the country are fast tracking the relicensing of retired physicians to provide backup. In Alberta and British Columbia, regulators have called for doctors who retired in the past two years to return to practise, while Saskatchewan will relicense doctors going back three years. In Ontario, retired doctors can obtain a "short duration certificate" that will enable them to practise under supervision for 30 days. Some provinces expect to process applications from interested doctors in as few as three days.

While it is still early days, many retired doctors have expressed interest in coming back to work, said Susan Prins of the College of Physicians and Surgeons of BC. "Everyone is doing their part to ensure needs are being met as quickly as possible."

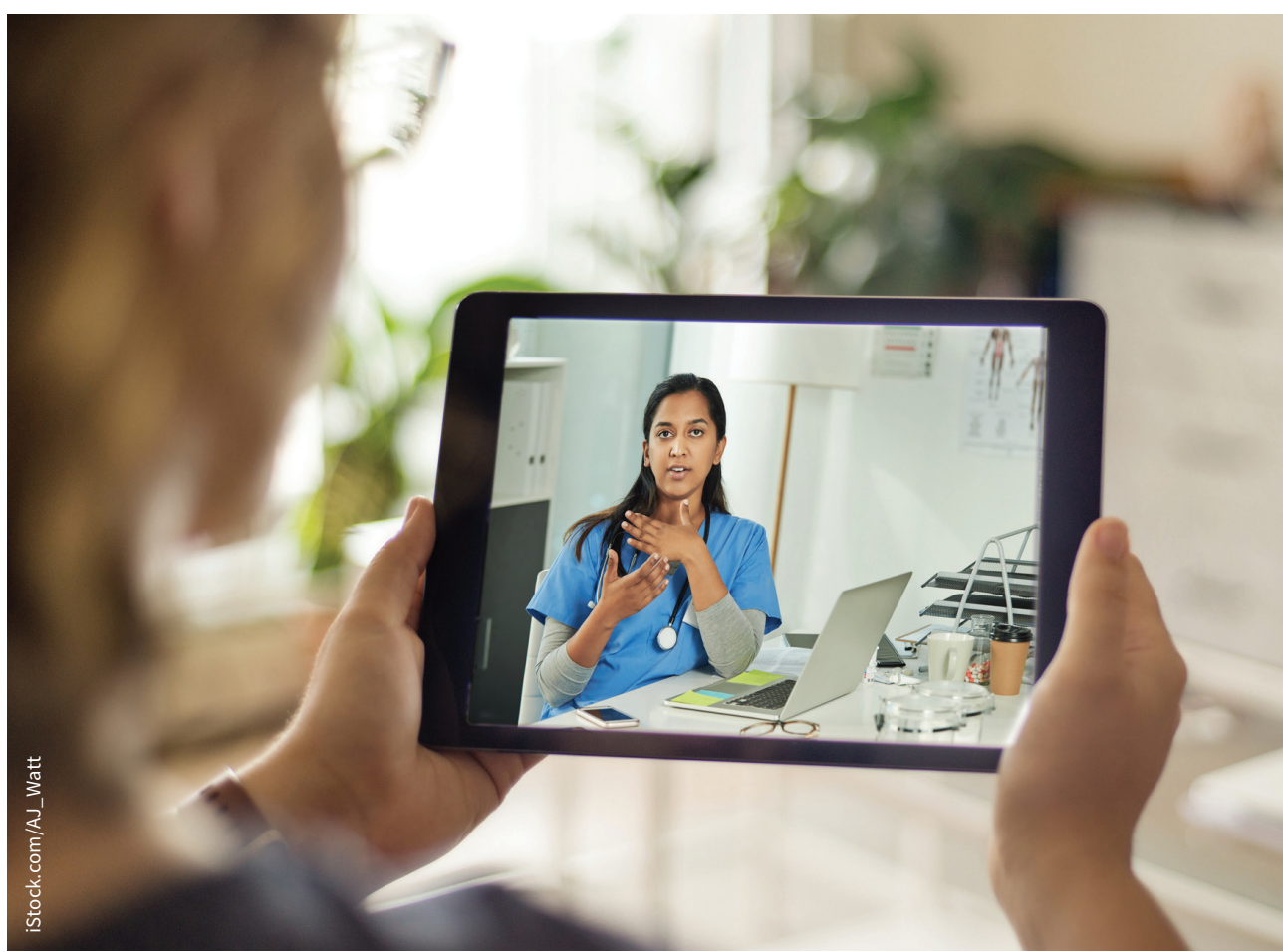

Health systems are working on creative ways to make the most of already strained health human resources.

According to Warner, the intensive care unit where he works at Michael Garron Hospital in Toronto is looking at increasing the ratio of patients to nurses to $4: 1$ (about double the ideal ratio for critical care). The hospital is also cross-training nurses from other departments to work in intensive care and considering using video conferencing to enable intensivists to oversee other doctors providing care at bedside.

"If I just had to make decisions, I could manage 100 patients per day," said Warner. "The documentation, the ordering, the schlepping from patient to patient, putting on personal protective equipment; that's what slows me down."

Respiratory therapists, who play a key role in operating ventilators in intensive care units, are also preparing for increasing workloads. According to Andrew West,
CEO of the Canadian Society of Respiratory Therapists, about $60 \%$ of their members currently work in critical care, but the rest are fully skilled to pivot to work in that area as required.

And although final exams have been postponed for medical trainees, the Royal College of Physicians and Surgeons of Canada recently announced that graduating medical students will still be able to obtain an educational licence to enter residency and graduating residents will be eligible for temporary licences to continue working.

The call for all hands on deck comes at a difficult time given chronic under-staffing and labour disputes in some provinces. Vicki McKenna, president of the Ontario Nurses' Association, said her province has been struggling with nursing shortages for several years now. There are hundreds of 
vacancies, particularly in northern Ontario and rural areas, and nurses are already logging "hundreds of thousands" of hours of overtime, she said.

McKenna hopes the province has learned from the 2003 severe acute respiratory syndrome (SARS) outbreak not to call in health professionals who take shifts at multiple sites to prevent further spread of the virus.

In Alberta, the relationship between health care unions and the provincial government is particularly strained. In November, Alberta Health Services served notice that it was embarking on a major restructuring that would include layoffs and not filling vacant positions, which led to outcry from health workers in the province. This week, the provincial health authority agreed to suspend contract negotiations and extend job protections until May 31.
The situation in Alberta is volatile, according to Heather Smith, president of the United Nurses of Alberta. "Overcapacity in the acute care sector has become the new normal over the past few years. On top of that, the health care workforce is feeling under attack, underappreciated, and disrespected," she said.

Family doctors in Alberta also raised concerns about a lack of support for virtual care to allow them to care safely for patients at a distance. The province recently launched an app to connect patients to family physicians virtually, but the platform functions like a walk-in clinic, so physicians cannot "see" their own patients, which affects continuity of care. Doctors also protested that the fee set for virtual care is the same rate $(\$ 20)$ as the government paid during the H1N1 pandemic more than a decade ago.
Most provinces have introduced billing codes to compensate physicians for consulting with patients by phone or video chat. Saskatchewan, for example, will pay physicians $\$ 35$ for telemedicine consultations. Ontario recently approved doctors to provide "routine health care" by video and telephone. Meanwhile, BC has temporarily expanded the scope of consultations covered by existing virtual care fee codes.

According to Dr. Kathleen Ross, president of Doctors of $B C$, efforts to increase virtual care capacity are already paying off. "There are some physicians who have self-isolated or been quarantined for a variety of reasons who have been able to use this platform to continue to care for their patients."

Greg Basky, Saskatoon, Sask. 